\title{
Oral histories, farm practice and uncovering meaning in the countryside
}

\author{
Mark Riley \\ Department of Geography, University of Portsmouth, Portsmouth,PO13HE, UK. \\ David Harvey \\ Department of Geography, University of Exeter, Exeter, EX4 4RJ, UK.
}

Building on recent analyses of 'heterogenous agri-cultures' this paper considers the potential of an oral history approach to explore the geographies of farming cultures and the processes of agricultural and landscape change. Drawing on case studies from the Peak District and Devon (UK) the paper advocates a less mechanistic methodological approach that taps into oral histories and offer a more nuanced appreciation of this change 'from the ground'. The understandings embedded within these oral histories are investigated with attention given to how these may contribute to recent discussions of the role of farmers' knowledge(s) in the current and future management of the countryside.

Key words: Landscape, Oral History, Farming cultures, knowledges, Devon, Peak District

\section{Introduction}

"In the province of rural skills and crafts the oral tradition holds much of the old empirical knowledge which is worth preserving.....scientists today are usually impatient of any claim that the old knowledgehas worth".

(Evans 1970: 18-19)

The work of George Ewart Evans, from which this extract is taken, is considered amongst the pioneering work of oral history in Britain (Howkins 1994). Evans's work attempted to 
interpret and record changing customs and working habits as well as changing dialects and language in Rural Britain. Paramount in much of this work was the desire to record information about changes to farming practices and how these were linked to shifting social patterns and transformation in the countryside (see for example Evans 1965; Evans 1975; Evans \& Gentleman 1993). Written against the wider academic background of scientific certainty and deepening faith in methods ofquantification and social modelling in this period, the extract suggests that little value was seen by 'scientists' in collecting oral accounts of this change. Although one may question Evans's faith in collecting merely for the sake of 'preservation' and the apparent sense of nostalgia and regret as the basic motivation for oral history collectors, one can also trace a strong sense of purpose through Evans's work, towards uncovering alternative, personalized, non-scientific and even subversive strands of knowledge. Strands, in other words, that heralded the labour historycentred, and often heroic, narratives of the History Workshop Movement of the following decades (Ross \& Wilentz 1981), and strands that perhaps can be traced in the overtly subjective and deeply contextualized narratives that reflect the so called 'cultural turn', which has more recently been witnessed in geography (Barnett 1998; Cook et al. 2000).

However, while such a sense of purpose that analyses and even celebrates the individual and subjective accounts of the countryside has been carried forward in the work of a number of historical and cultural geographers interested in issues of landscape meaning, rural transformation and cultures of the countryside, they have largely done so through the exploration of the writings (and artwork) of specific, and often privileged, individuals, leaving the methodological approach of oral history as a fairly neglected toolkit within such studies. ${ }^{1}$ Indeed, in assessing the impact of geography's 'cultural turn' on the 
discussion of rural and countryside change, Morris and Evans have noted the paucity of more in-depth qualitative approaches, calling for greater attention to be paid "to cultural constructions of different groups" (Morris \& Evans 1999: 354 emphasis added). More recently, Morris and Evans imply a gradual progression of academic analyses of 'heterogeneous agri-cultures', calling for further research that can move "beyond the sometimes rather descriptive and insular accounts....and mechanistic methodologies" (Morris \& Evans 2004: 104). This paper contributes to this deepening discussion of 'farming cultures' and increasing methodological sophistication through an analysis of two studies undertaken in the Peak District and Devon (UK) respectively. The objective of the paper is to develop and consider the potential of an oral history approach to explore the historical geography of farming cultures and the processes of agricultural and landscape change. This overall objective brings together three interrelated aims. The first is to develop and assess the potential of a less 'mechanistic' methodological approach that taps into oral histories of landscape change. This aim considers innovations such as interviewing 'in-the-field', sequential and group interviews, together with the use of artefacts, in order to help capture the understandings and influence of 'neglected rural others' who have often been marginalized in previous discussions (see Philo 1992). The second aim is to consider the knowledge and understandings that are embedded within these oral histories, and explore the ways in which they can engage with debates over landscape development and changing agricultural practice. Thirdly, the paper considers how these understandings embodied within farmers' oral histories may intersect with, and inform, current efforts aimed at the conservation of rural landscapes, contributing to recent debates about the role of farmers and their understandings in the current and future management of the countryside. 


\section{'Oral History' and farming cultures}

Oral history has a long and contested genealogy, often being used as an all-encompassing shorthand both for the practices of interviewing or 'recording' oral testimonies, as well as the resulting testimonies themselves - either in recorded or transcribed form (for useful reviews see Nevins 1996; Thomson 1999). Within this paper, we regard 'oral history' as verbal recollections of events from one's lifetime. We differentiate this from 'oral tradition', which we see as a body of knowledge transmitted orally over several generations - that is, understandings which move beyond the life history of one individual. ${ }^{2}$ We draw, therefore, on oral histories in the form of 'life history', which Titon (1980: 283) defines as an "account of a person's life based on spoken conversations and interviews". In particular, we use the concept of the 'topical life history', which focuses upon one specific aspect of a person's life - in this case the theme of agricultural and rural landscape change (Denzin 1989: 42). ${ }^{3}$ We move beyond previous qualitative research, which has mostly used the semi-structured interview (or interrogation), towards an approach which elicits more 'conversational narratives' (see Grele 1998). As such, we seek to develop methodological approaches that facilitate a dialogue in which the concepts, terminologies and categories of the interviewee can be set out in their own words. This occurs through the use of in-thefield' discussions, sequential interviews, and the use of personal artefacts, alongside intergenerational and group interviews.

Taking forward this innovative methodological approach, the paper turns to consider the potential of these oral histories to answer recent calls from cultural geographers to move towards a more nuanced understanding of the transformation of the agricultural landscape 
'from the ground' - through the experiences and understandings of the people who have enacted these changes (Setten 2004; Setten 2005). We consider that oral histories can provide a crucial social element to these understandings of change and contribute to the wider discussion of 'agri-cultures', which develop "newunderstandings of farmer identities and farming lifeworlds" (Holloway 2000: 308). In particular, this research has been informed by the (re)consideration within cultural and historical geography of the precarious power-knowledge relationships between science and other modes of understanding, in relation to the practice of geography, and specifically relating to agriculture (see Burgess et al. 2000; Lorimer 2003; Philo 1998; Tsouvalis et al. 2000). ${ }^{4}$

Recent investigations have turned attention to the 'knowledge-cultures', or 'knowledge communities', which have grown around the broad areas of landscape management and conservation, and which focus on the cultures of knowledge creation and legitimisation at the interface between farmers and scientists (see Morris 2006; Raedeke et al. 2003; Tsouvalis et al. 2000; Riley in press). This paper develops and extends these research trajectories by considering an oral history approach as a means of unveiling these other understandings. As Portelli (1981: 99-100) has suggested, oral histories have the potential to tell us "not just what people did, but what they wanted to do, what they believed they were doing, and what they now think they did". Oral histories, therefore, have the potential not only to contribute to the discussion of landscape change, but also to help understand the processes of this change.

At a practical level, the importance of considering the history, changing nature, and evolution of farming practices is highlighted by their centrality in contemporary 
countryside policy, with the latest Rural White Paper, for example, arguing that "[m]ore intensive agricultural practices have been the major contributor to the decline over the past 50 years in farmland birds, wild flowers and insects", and adding that "one of the Government's Public Service Agreement targets is to reverse this decline, by promoting agricultural practices which enhance biodiversity" (DETR/MAFF 2000: 126). Moreover, at a conceptual level, through investigating alternative narratives of agricultural practice, we are able to follow Setten's (2004: 392) call "to understand the production of a landscape from within, or how the landscape is the result of local customary practices". The life histories of farmers have the potential to make a contribution in this direction, furthering our understandings of agricultural practices. As Thompson (1981:289) suggests, "the value of life histories lies in their roots - they are rooted in real experience and are, therefore, capable of generating wholly fresh sociological insights as opposed to the self-reflecting answers of predetermined questions". Such an exploration of the oral testimony of farmers as practice based and place bound narratives can allow a more socially enriched understanding of landscape change and the practices associated with this change, thus heeding Creswell's (2002: 280) challenge to historical-cultural geographers to "produce geographies that are lived, embodied, practised; landscapes which are never finished or complete, nor easily framed or read". In exploring these socially enriched alternative narratives of landscape change, space is opened up for a more critical questioning of contemporary conservation management policies, and how these intersect, conflict with and maybe are enriched by the oral histories of famers.

Following a short introduction to the two case studies, the paper considers the innovative methodological approaches that were employed and developed within the projects. The 
following two sections move on to deal specifically with the information on landscape change and agricultural practices that are embedded in, and forthcoming from, the oral histories. We then briefly consider how these oral histories intersect with contemporary countryside conservation, before drawing together some conclusions.

\section{The oral history approach in Devon and the Peak District:}

The two regions studied have become iconic, both in landscape studies generally and championed specifically in relation to landscape conservation measures (see Edwards 1973; Hoskins 1954). Both regions contain large areas designated as National Parks, Areas of Outstanding Natural Beauty, and a wide range of more site specific environmental designations such as Environmentally Sensitive Areas (ESAs), National Nature Reserves (NNRs), and Sites of Special Scientific Interest (SSSIs). In Devon, research specifically considered the period of the Second World War (WW2). While there has always been popular interest in the wartime era, Howkins (1998: 75) has argued that, from an academic perspective, "the history of rural areas during the Second World War is virtually unstudied". Indeed, listing just a few disparate studies on the agricultural policies of the period, Howkins (1998: 75) notes that "the extent to which these rely on K.A.H. Murray's 'official' history published in 1955, is testimony both to the quality of Murray' work and the paucity of more recent published research". While Murray's 'official' history, together with that embodied in the National Farm Survey (NFS) of 1941-1943 (Short \& Watkins

1994; Short et al. 2000) create a meta-narrative of landscape and rural change in the period, few studies have investigated the knowledge and understandings held in the oral histories of the farmers and farm workers who were charged with instigating this change. ${ }^{6}$ 
The Peak District study concentrated on the practice of haymaking and hay meadow management since WW2. Historically, hay production was a widespread activity across the whole of the UK, with the very particular management regimes of cutting, turning and drying, as well as low inputs of farmyard manure, creating a very specific habitat supporting a wide range of wildlife (Hughes \& Huntley 1988). From the late 1800s onwards, an array of changes resulting from a modernising agriculture began to alter the management systems that maintained this complex balance. In addition to land drainage, the more widespread use of temporary grass leys, inorganic fertilizers and herbicides, was the development of silage production (see Brassley 1996). With the development of silage came changes to the way in which hay meadows were managed, including earlier and more frequent cutting, less desire and need to dry grass and thus less seed dispersal in the turning process, as well as greater use of fertilizers and chemical inputs. These changes culminated in the widespread destruction of hay meadows, with estimated losses of up to $97 \%$ in the UK (NCC 1984). Subsequently, there have been a number of efforts to conserve and enhance the nation's stock of hay meadows with many regions featuring them as a priority habitat within their Biodiversity Action Plan (BAP) (See for example PDNPA 2000). ${ }^{7}$

In total, oral history interviews were undertaken on 64 farms in the Peak District and 23 farms in the Devon study. In both projects, the areas studied were 'purposively' (after Mason 1996) selected in relation to different landscape types. ${ }^{8}$ With definitive registers of either farmers undertaking haymaking practices (Peak District) or those who experienced farming during WW2 (Devon), lacking, respondents were what Heckathorn (2002) calls a 'hidden population', contacted through chain referral sampling. Initial contacts made though a variety of sources were asked to refer other, future, respondents. 9 


\section{Uncovering oral histories of change}

\section{Being 'in-the-field'}

An important aspect of assessing the potential of life histories was the process of speaking to and recording farmers 'in the field', that is, whilst walking around the farm. Within the broad discussion of qualitative methods, and more specifically in relation to oral history, the location of interviews has been seen to be an important 'fact of creation' (Grele 1979: 34), with the context in which the research encounter takes place often provoking memories and insights into the understandings and self-conception of the respondent (Cook \& Crang 1995: 8). What was highlighted through the use of this in-the-field approach was how recollections were stimulated by, and grounded in, the landscape, acting as, what Marcombe (1995: 14) has called, a 'topographical starting point'. The two following short interview extracts illustrate how these ideas worked in practice. The first is taken from a discussion during a farm walk in south-west Devon:

This land was what was kept as tilled land as the soil is slightly better quality, if you look just over the river you move onto rougher land. ${ }^{10}$ You can see the ridge in that field, that was where that was ploughed during the war... and the corner of that next field was taken out for two acres of potatoes...oh and then in the distance, the rough land was taken bythe War Ags ${ }^{11}$ for improving

In standing at this vantage point, markers in the landscape acted as a prompt to the farmer's narrative of ploughing land in WW2. After this initial process of 'locating', the farmer was asked about each individual field, focussing on questions such as why that land in 
particular was selected to be ploughed, and how long the land remained in cultivation after the war. These points fed into wider discussion of the role of state intervention during and after WW2, as well the farmer's thoughts and opinions on current conservation efforts. It was found that by actually being in the field, particular issues could be returned to more easily than where interviews were set indoors. For example, in the south-west Devon interview, the farmer was later asked "you said that field [pointing to the field] was rougher than the other one, what did you mean by that?" The fields could be used as markers in the narrative that the farmer was developing, and the farmer was able to quickly move back in the narrativeand embellish the issues raised. ${ }^{12}$

This second extract is taken from an oral history interview in the Peak District:

This meadow we are standing in has always been a good growing meadow. Even though it's a windy day, you can feel that it doesn't catch it here. It faces the right direction to catch the sun, whereas the field over the river doesn't get the same sunlight [...] it's on a different understone than further down... as you can see, the fields in the distance are darker in colour where you move onto the gritstone

By conducting the interview in-the-field, the oral history was embellished further than would have been possible if the discussion had taken place elsewhere, with the detail of the meadow being 'good growing' furnished with the reasoning behind the farmer's categorisation. In addition, the farmer's narrative was furthered by being able to illustrate these issues in situ, drawing upon a multi-sensory experience of the land in order to illustrate such intricacies as the degree to which land might be sheltered from the wind. 
While other researchers have made general reference to the importance of interview location, what is extended here is the importance of these familiar locations and contexts to embellishing the research findings as grounded stories about a person's day-to-day life in that place, with "illustration and corroboration [...] easily be made through reference to objects near at hand" (Cook \& Crang 1995: 38). The dynamic nature of interviewing in this way opened up space for more incidental paths to be followed as interviews developed and literally processed/proceeded around the farm. One of the clearest examples came in north Devon where a defunct tractor was encountered in the respondent's field (Figure 1). The tractor embodied a rich past, as it had been bought from the local War $\mathrm{Ag}$ and represented an important phase in the farm's history, with its purchase allowing more widespread ploughing of land, and initiating a period of moorland reclamation. As the tractor was literally uncovered by the farmer, it acted as a spur to several new trajectories within the life history.

[Figure 1 near here]

\section{Artefacts}

The example of uncovering the defunct tractor leads to a second important methodological approach developed within the research - the use of artefacts and interview prompts. Particularly where 'in-the-field' discussions were not possible, artefacts were often used as prompts within interviews. In the Devon study area, the NFS maps and returns were invaluable in this respect. ${ }^{13}$ These were used to both question the 'official' narrative generated and preserved by the NFS as a whole, ${ }^{14}$ and to inform wider issues such as the location of particular landscape features and the practices associated with landscape change 
more generally. More important in this respect was the approach of encouraging respondents to bring their own artefacts into the discussion. As Cook and Crang (1995: 67) have argued, "people invest meanings and significance in the material objects around them", and in our case studies, we found that respondents commonly brought forward pieces of farming equipment which they used in their narrative of changing agricultural practice. From these recollections, interesting links to contemporary conservation management practices were possible. For instance, in the Peak District a farmer illustrated his narrative of how the mowing of meadows had taken place prior to mechanisation with an old scythe, which prompted further discussion of cutting and the decline of meadow fauna - an issue which is now central to conservation discussions (see Smith \& Jones 1991):

'With a scythe [illustrating the swing technique used to cut the grass] birds were not threatened...you were right in the field and could spot the nests...you could work around them or move them to a safe place [...] now they are mowed straight over with tractors...it's the same with rabbits...with scythes it was slower and they could move out of the long grass to safety...now tractors come in and whiz around the outside and trap them in the middle 15

A more common set of artefacts used during discussion comprised respondents' photographs. On one level, these were used directly in relation to landscape change, with old photographs illustrating the discussion of trees, hedgerows or drystone walls for example. At a deeper level, however, such photographs, as Walker and Moulton (1989: 182) have suggested, capture "complex memories, express the deep feelings, and bind 
together fragmented experiences of modern life [...] into more or less coherent visual statements". The interviews were used as a means of exploring and unpicking the complex histories embodied in these photographs. This was illustrated in the Devon study when a picture from the 1950s of a haystack and several farm workers was brought into the discussion by an elderly respondent. The raison d'être of the respondent in introducing the photograph was to illustrate the technique of building haystacks prior to mechanised collection of hay and straw. However, from the photograph several other trajectories to the discussion developed. First, the photograph prompted a prolonged discussion of the social importance of harvest time, of kinship ties, and the decline of travelling gangs of workers who had historically played an important role in harvest activities. ${ }^{16}$ Second, was a more detailed discussion of the interrelated nature of management practices, whereby hedge trimmings were used to form a base on which the subsequent stack was built (discussed in Riley \& Harvey 2005: 276). The farmer went on to discuss how, when the necessity to build hay and straw stacks declined, the associated trimming and management of hedgerows also ceased. Illustrated here is both the methodological potential of using such artefacts within the research process, and the intricate, and often unwritten, social histories, which these oral histories carry forward.

Methodologically, artefacts can act as a spur to particular stories and aid the narrative being created, and, as in the example of the scythe above, can provide a means of articulating more clearly, both physically and verbally, issues such as the changing nature of farm practices. The ensuing oral narratives can unpick the intertwined and complex histories that are embodied within these artefacts. As the example of the haystack photograph suggests, artefacts may take the narrative into less immediately obvious directions which unveil 
important and often hidden social histories, which can be seen to undergird changes in practice and wider landscape development.

\section{Moving Away from the Snapshot}

A criticism levelled at much of the research to date on farming cultures has been that it has taken a 'snapshot' approach which has considered the understandings, opinions and lifeworlds of farmers at just one specific point in time (Morris \& Evans 2004: 104). The advocacy of an oral history approach, in offering a longer-term perspective, moves away from such present-centred, snapshot approaches, particularly in connection to sequential interviewing. Sequential, or serial/multiple interviewing, involves the revisiting and (re)interviewing of respondents, and was found to be an important technique in several key respects. First, on a practical level, the nature of the studies meant that they often involved older people discussing complex memories for long periods of time. Revisiting removed the need for long and tiring discussions, while giving extra space to discuss the voluminous issues raised that could not be covered during one session. More fundamentally, however, the technique allowed a rapport to be developed between interviewer and respondent: something that has been described as "the key to the art of interviewing" (Valentine 1997: 110). While the issues of landscape development and changing agricultural practices are ostensibly inert topics, the oral history approach meant that these topics were bound up with private personal and family histories. Therefore, developing a rapport with respondents over several visits allowed these histories to be addressed and told more easily. Return interviews also allowed information to be cross-checked. This was not a question of bringing forward and checking 'right' or 'wrong' 'facts' (although there were numerous cases where factual details were corrected in subsequent discussions), but to explore which 
events, stories and issues were returned to more frequently than others and hence which could be recognised asmore important.

Revisiting respondents often facilitated a change of interview location - in particular a move from indoors to in-the-field interviews. ${ }^{17}$ Issues raised in previous discussions could be illustrated and embellished fully though visual examples: "That's the banked hedge that I was telling you about last time"; and performed demonstrations: "I'll show you what I meant when I told you about the splitting of stalls to lay a hedgerow". In addition, the scheduled revisit allowed artefacts to be located and brought out, such as the scythe discussed earlier. During one interview for instance, a retired farm worker commented: " $I$ found the picture of the ransome plough that I told you about in the bureau... and I dropped on a letter that one of the prisoners of war sent after the war...I don't think I told you about that?". In the ensuing discussion, the farmer revealed the role of the prisoners of war in land reclamation on and around his farm during WW2, outlining how this abundance of free labour had led to an unprecedented level of land drainage that had significantly increased the productivity of the land, and appreciably changed both the physical landscape and the nature of agricultural production in the area.

An issue that came through strongly in connection to both serial and group interviewing was how success depended so much on interview context. While a series of meetings could be used to establish a sense of trust and build a positive interview 'dynamic', some situations sometimes had negative consequences, particularly in connection to certain group interviews. Two examples from Devon, both involving carers for elderly respondents 
serve to illustrate this point. In the first example the carer intervened on several occasions to shape and direct the interview:

Respondent: The committee took on a lot of land for reclamation...

Carer [interrupting] Tell him about the home guard George ${ }^{18}$

Respondent: Yes, well there was the home guard down in the village...

In a second example, a return interview revealed how the farmer had censored the account she had given in a first interview when her carer was present. Even though the carer had not participated or intervened in the discussions, the second interview revealed several instances where the respondent noted that "I didn't want to say that in front of Mary" and "it was something I'd rather Mary didn't know about". These examples illustrate the importance of interview dynamic and how, in these cases, self-censorship could take place depending on the presence or absence of others. On the flip side of this, the presence of more than one respondent could often facilitate a positive and fruitful interview dynamic.

Morris and Evans (2004) have suggested that a weakness of previous research into farming cultures is the application of methodologies and sampling strategies which have privileged predominantly male farmers considered to be the 'principal operator'. They point out that "groups within agriculture such as non-family hired workers, contractors, $[\ldots]$ shepherds, rare breed keepers and independent women farmers [...] remain sorely neglected" (Morris \& Evans 2004: 104). Consciously moving away from the 'expert witness' of principal operators, the Devon study commonly involved interviews with farmers' wives and children, farm workers, former land girls, agricultural contractors and employees of the 
'War Ags'. Within the Peak District, where attention focussed upon changing agricultural practices, participant observation was undertaken on 20 farms which, as discussed later, gave access to a workforce which, due to their transient and sporadic presence on the farm, would have not normally figured prominenty within farm interviews.

A key advantage of group interviews was the ability to 'triangulate' data between different respondents (after Denzin \& Lincoln 2003). Moving beyond the idea of triangulation as a means to 'confirm facts', group interviews enabled us to get beyond singular narratives that were dominated by prominent individuals. This approach was important in two main ways. First, interviewing more than one person allowed corroboration and collaboration in which respondents were able to bridge gaps within each other's narratives. Secondly, group interviews sometimes undermined assumptions about the role of the 'principal operator', by reaching the voices of people who might otherwise have been hidden. An example from the Peak District illustrates the former process:

Respondent 1: The first move to silage production would have been [pause] Respondent 2 [Intervening] In 1971, when John next door bought his equipment....

Respondent 1: ...Yes that's right and from then we gradually moved away from making hay.

In addition to this bridging of narratives, group interviews also revealed the process of 'relaying', where respondents passed the discussion from one to another. In terms of allowing alternative narratives and understandings to be articulated and debated, group interviews commonly offered different perspectives and recollections: 
Interviewer: Who carried out the ploughing of land for the committee?

Respondent: [deferring the question to his wife] Who came here to do the ploughing for the committee? [Continuing after wife's response] ... you see my wife was here. I spent a lot of time running the home guard and didn't see some of these things like she did

Similar examples, which offered alternative perspectives, were seen to be important in relation to issues such as gender, age and status. For example, it was found that farm workers or labourers often had a more intricate experiential knowledge of land management and landscape change than those who owned or managed the farm. As one retired farm worker noted: "We were the ones on the land...doing the everyday work on it...the boss managed us from the yard and didn't understand the land as well as we did". Along similar lines, it was found that gendered divisions of labour often meant that, in adhering to patriarchal structures, male farmers demonstrated a clear understanding of the hands on 'practice' of land management, while their wives had been responsible for the administration of paper work, and thus offered a more informed perspective on the changing nature of government policies. A particularly good example of this involved the daughter-in-law of a farm owner in the south-west Peak District, who discussed the management of the hay meadow and its entry into a conservation agreement: "I was interested in the birds and conservation... when the conservation schemes started, I read up on them and explained them to my father-in-law...I persuaded him to put them in because he was managing them sympathetically anyway". This illustrates how even when respondents were not directly employed or living on the farm, they could still offer both 
alternative narratives of a farm's history and also highlight a crucial, although undocumented and under-recognised, role in shaping this history. . In addition to allowing an exploration of generational differences in opinion of certain issues, ${ }^{19}$ intergenerational group interviewing also allowed commonalities to be identified in the way issues were recollected and narratives structured. Similar to the idea of 'family-tree interviewing' advocated by Slim and Thompson (1998: 117), it was possible to see how key figures within the family, both past and present, became central to the discussion of certain practices or critical times in the farm's history.

\section{Landscape change and oral testimonies: biography and genealogical knowledge}

A wider criticism of using oral history is the suggestion that there is no such thing as pure recollection, and that memory becomes rewritten over time (Hobsbawm 1997; Thompson 1988). Critically within this research however, the respondents' oral histories of landscape change do not stand as 'pure recall' but were inscribed on, and stimulated by, the physical landscape. In this respect, the landscape becomes a contextual cue from which the oral history proceeds, and acts as what Confino (1997) refers to as a 'vehicle of memory'. As one farmer recalled as he walked across his farm:

The track that you can see running through the middle of the field is where we used to take the stock to the river to drink...before the 1930s when we were connected to the mains water

This example highlights the way in which recalling landscape development and agricultural change was not an abstract process, but rather the material landscape carries forward 
understandings which become co-constructed, unpacked and narrated by farmers. Taking their cue from the physical landscape, such oral histories were commonly intertwined with biographical events, which allowed a temporal structure to be added to recollections. The ways in which landscape change is remembered and recalled, therefore, is seen as relational (cf. Setten 2004), such that they are located and contextualised in relation to other events. In the Peak District for instance, one farmer intertwined the mowing of a particular piece of land for hay and his niece's wedding in recalling the history of the land:

I remember cutting it on the day of our niece's wedding. That would have been June the $4^{\text {th }}$. I came home and cut it in the evening between the wedding and the evening reception

Other farmers used longer biographical narratives to provide a temporal map of agricultural development on their farm. For example, an 84-year-old respondent in north Devon referred to the improvement of his family farm, traced alongside the biographical events that had been important in bringing about these changes:

When I left school in the early thirties there was now me, my dad and uncle and we took on more land. When I got into my twenties we started to reclaim some of the moorland, ploughing and adding lime... and when I got married, that was when I was twenty-four, we bought the farm next door too...that allowed me to farm on my own, and to start intensifying the farm for my sons 
Drawing on biographical events in this way has parallels with what Green (2000: 26) has referred to as 'linguistically appropriating the landscape', whereby "in the memories of a particular place, the landscape and its human occupants may become almost indivisible". Farmers' oral histories of landscape change commonly went beyond recollection from personal biography and experience, and incorporated a wider genealogical framework, reflecting Setten's (2004: 396) remark that "farmers embody their past practices, both their own and that of their ancestors". Sometimes, aspects of a deeper past, beyond the living memory of respondents, were used to date particular events, with responses such as "the land was bought in the 1800s when my great-grandfather moved to the area", or the "moorland was all burnt by a fire in 1903 when my father was born", representing a longer oral tradition or 'genealogical knowledge'.

Some oral histories held information that had been passed through several generations, often relating to material that had not survived in either physical or written form. This was clearly illustrated in an example from Devon, where a farmer discussed a recent meeting with archaeologists regarding the presence of historic features on his land. The Devon County archaeologists had not accepted his belief that a now ploughed field had contained artefacts of archaeological value. Enlisting the advice of the Heritage Lottery funded Community Landscapes Project ${ }^{20}$, the farmer explained that "even we knew there was something out there, we wouldn't have called it Garden Plot otherwise". Indeed, subsequent investigation revealed that the land had been a former settlement and garden, illustrating how oral histories contain knowledge of the past, even when the respondent is not fully aware of its origin. 
A parallel can be drawn between this example and Ohrn's (1975: 27) discussion of the relationship between oral histories and family photographs, whereby the photographs may act as 'documents of family life', which serve to sustain a family's links with its past and provide a way of transferring an awareness of family history to the next generation. A similar relationship exists between oral history and landscape change, with the landscape becoming a way in which farmers understand the work of previous generations, who inscribed their own meaning and identity onto the landscape. These inscriptions and markers can embody important phases in a family's history, with subsequent generations looking to build on and develop this work - or as one farmer suggested - "carry on the work that our ancestors have started". ${ }^{21}$ For many farmers, therefore, the material landscape sustains links to the past and oral histories carry forward an awareness of the intricacies and detail of this past. In this way, oral histories provide a rich source through which to understand landscape history and landscape change both in the recent as well as deeper past.

\section{Narrating Practices}

A more particular way in which oral histories and agricultural landscape change interact is through being embodied in particular practices, or what Connerton (1989) has referred to as 'embodied memory'. Hoelscher and Alderman (2004: 350) have noted that "[w]hile the constitutive relationship between memory and place is most obvious in the realm of material culture - in landscapes - it is also, and no less, performative, through bodily repetition and the intensification of everyday acts that otherwise remain submerged in the mundane order of things". Oral histories of farming practice reveal how aspects of the past become embodied through the repetition of performative agricultural practice. A pertinent 
example of this was uncovered during the participant observation in the Peak District, where the process of standing hay bales into a tripod system was witnessed (figure 2). The father of the current farmer followed the hay baler around the field and stood bales in this

manner before they were loaded onto a cart and cleared from the field. The practice appeared illogical, particularly since the bales were collected almost immediately after baling. Indeed, the retired farmer only managed to erect a small number of bales in this way before a team of workers cleared all the bales in the field. When asked about the practice, he recalled:

It's how it was all done in the past, before there were balers. You'd put the hay together into a cock to stop it all getting damaged by the rain...later on they built special tripods out of wood and you would hang the hay over them so it would help it dry, especially if there wasn't much sun [...] when we first had balers they were slower than today we put them all like this ...until we had time to fetch them. Sometimes they might stay out for days before we collected them, so this cut edge [see figure 2] would cast the rain off. Now they are cleared off so quickly with tractors and loaders... .

[Figure 2 near here]

While the farmer's oral history did not unveil an unidentified practice per se - the practice of 'cocking' hay on 'tripods', before the use of mechanical balers, to avert weather damage has been recorded elsewhere by agricultural historians (see Knape 1955) - it offers insights into the methodological potential of such an oral history approach. First, such oral histories 
can offer an understanding of previously necessary practices, which have largely disappeared from the contemporary landscape. Secondly, these oral histories can open up questions as to why such relicts as these seemingly 'redundant' practices persist today. In elaborating further on the practice, the farmer discussed how the 'cocking' of hay had been important in an era before mechanisation, and argued that even with mechanical baling and more rapid collection from the field, the cocking of bales in this way could deflect water and avoid the risk of weather damage. ${ }^{22}$ Critically, in being allowed to explore more fully the life history of these practices, the farmer brought forward an explanation of the intermediary period between the pre-mechanised cocking of hay and the 'relict' practice he now undertook. The following extract is taken fromthe interview in-the-field:

When we collected hay loose it wouldn't sweat and fire ${ }^{23}$, with balers the grass is compacted and makes it more likely to heat up...if you stand them up the air can circulate and reduce the risk, that's the way I looked at it...over time turning and baling equipment has improved and dries it much quicker so it doesn't sweat as much.

While the earlier extract, in which the farmer drew explicit links between the current practice and its origins, may ostensibly lead us to question his current practice as a nostalgic relic, a broader discussion of the practice's full history reveals an intermediary period in which the meaning of the practice changed significantly. Oral histories such as this highlight the very intimate and experiential nature of knowledge that farmers have. Knowledges, in this sense, are reflective, adapting to changes in situation - in this case, mechanisation and the associated problem of combustion. Methodologically, the example 
highlights the possible problems in generating meta-narratives of changes in practice, particularly when more 'rigid' questionnaires and structured interviews do not leave space for more complete histories to be sketched out and developed. While a direct link could perhaps be made between the current practice and its origins, a more complete understanding is only revealed when the dynamic history of the practice is fully contextualised through oral narrative. In addition to cautioning against these temporal meta-narratives which may mask critical periods of a practice's history, the example of cocking hay bales highlights the spaces that oral histories may provide for regional variations and local adaptations to such practices. Farming practices are not ubiquitous, and show delicate and often idiosyncratic variation at the micro-level, which reflect the diverse farming cultures that surround them.

Furthermore, oral histories were seen to underscore the cumulative nature of experiential knowledge. During an interview in Devon, one farmer remarked that:

This land had never been tilled. It was ploughed in the past, before my fathers time, and they said it had a very shallow top soil and wouldn't grow anything [...] it was set down to grass and has been like that ever since...you can't change the land you've got.

This example illustrates how current practices are underpinned by a cumulative understanding that often stretches back over many generations. These practices are based not only on the experience of trial and error by the current farmer, but also upon understandings that have been passed from previous generations. Commonly, this 
'genealogical knowledge' was carried forward as part of a rich biographical narrative of locally specific and contextualised farming life. In many cases, these understandings were crystallised in mnemonic devices, ranging from general and popularised sayings relating to weather such as "red sky at night, shepherd's delight", to more localised sayings relating to the specific nature of individual farms and their management. For example, a farmer in Devon referred to a saying passed from his grandfather that related to the family farm: "further from the farm, closer to the clay". In this case, the farmer went on to explain how the deeper topsoil of the land close to the holding still dictated the way in which he could plant crops around the fam.

\section{Oral histories and the conservation of the countryside}

The previous sections have illustrated the ways in which oral histories bring forward complex, intricate and unwritten narratives of change, relaying the locally-specific, intimate, tacit and experiential knowledge that many farmers have of these changes. We now turn to consider how these oral histories may also contribute to a more critical questioning of contemporary efforts at countryside conservation.

\section{Records from the ground}

At a basic level, the intricate understandings of landscape that are embedded within the oral histories of farmers can inform the locating of 'priority' habitats and features for conservation purposes. While such an endeavour may seem simplistic - given the recent levels of investment into conservation research and the increasing sophistication of techniques for the location and monitoring of priority habitats - it was seen that there are vital areas where oral histories can make a contribution. This was highlighted most clearly 
in the discussion of hay meadows and their decline. While official estimates suggest that as many as $97 \%$ (NCC, 1984) of hay meadows have been lost in Britain, actual figures are very sparse. There is no definitive register of the extent or location of meadows in the past, and major difficulties remain in locating such changes through remote sensing techniques for example (see Riley 2005 for a fuller discussion of these sources). Through years of continuous management, however, farmers often have an intimate understanding of the nature and variations of their land. For example, one farmer noted that "I have spent a lifetime working this land and know its every detail...every inch of it and the changes that have taken place here". The detailed oral histories of farmers, therefore, are often the only means through which the location of meadows, both and present can be explored.

The relevance of these locally-embedded understandings is highlighted when 'lost' hay meadows are considered. Pinpointing the previous location of hay meadows is crucial for the practice of reinstating hay meadows from former seed banks (see Smith et al. 2002). However, as figure 3 demonstrates, changes in management mean that areas previously used as hay meadows are now indistinguishable from other areas of land. ${ }^{24}$ The following extract is taken from the discussions with an 80 -year-old farmer relating to the land in figure 3:

When I was a child we mowed it with scythes and horses...the steepness didn't matter then you see? [...] we gradually mechanised things after we purchased a tractor from the War $\mathrm{Ag}$ in $1948 . .$. then the land was too steep to go on with the tractor and machinery so it was turned over to grazing and has been managed like that ever since. 
Within this oral testimony, the farmer's and field's life histories intersect to give a more contextualised reading of thelandscape. Akin to what Setten (2004) hascalled a 'reading of the landscape from within', this particular case stands as testimony to the view of Mitchell (2003: 237) in seeing landscapes as social products; as "labo[u]r ossified, concretised, and materialised". Through carefully analysing and unlayering narratives of change, more nuanced understandings can be found which can feed into current landscape conservation debates, often filling crucial gaps in the existing record. While these records of landscape change are in themselves important, particularly fruitful engagement is generated through oral histories of the practices that contemporary conservation schemes now seek to direct. ${ }^{25}$

\section{[Figure 3 near here]}

\section{Complementing Conservation Practice}

Oral testimonies can make a unique contribution to debates surrounding contemporary conservation practice and policy construction. In the Peak District, biographical markers were used by farmers to generate a chronology of changing agricultural practice that is of direct relevance to current debates around the management and phenology of hay meadows. ${ }^{26}$ The following extract is from an 80-year-old farmer discussing the management of one particular field during an in-the-field interview:

We were instructed to plough the field during the war and it was planted with potatoes. We stopped ploughing it when the war effort was over and went back to 
using it for hay.... Three years ago my son joined the Stewardship ${ }^{27}$ and they asked us to put it in...because of all its flowers and herbs.

While the qualitative nature of the farmer's oral history may appear distanced and ostensibly irrelevant to the precise science of ecology which predominates the management of hay meadows for conservation purposes, when unpacked it demonstrates a unique ability to make a link between 'biodiversity' and past management. The farmer's oral history of the meadow shows that even after complete disruption of the sward through ploughing, over a sixty-year period it was able to recover a high level of diversity. The importance of such a temporally deep understanding is illustrated when considered alongside current ecological research into hay meadow management. While much is being gleaned from scientific field trials, authors such as Smith et al (1996) have suggested that it may take between 10 and 20 years for conclusive results to be gained on the exact impact of certain management schemes on meadow diversity. Oral histories, therefore, are uniquely placed to illustrate and understand longer-term impacts of particular managements - projecting back in time to link the current status of meadows to very specific past events and practices.

As well as offering a deeper temporal framework for the broad changes to hay meadow management, oral histories can also allow examination of the specific fate of individual species. During discussion with a farmer in the south-west Peak District for instance, the crucial issue of the order and timing of meadow cutting was brought forward. Recognising the importance of such localised chronologies, the farmer noted that cutting had always taken place first in the same meadow, and that the subsequent schedule of mowing meadows had proceeded in the same order for many years. During the discussion, he 
referred to two particular meadows that were isolated from the farm and which, due to the difficult access to them, had always been cut towards the end of the haymaking season, and never before the end of July. The difficult access meant that these two fields had only sporadically received light applications of farmyard manure, and had never received any inorganic fertilizer. In broad terms, the historic management of these two meadows specifically their later cutting - had been closely aligned to that prescribed in agrienvironment schemes, and so they were entered into a conservation agreement in 1998. During discussion of these fields however, the farmer pointed to the abundance of the particular species 'yellow rattle' (Rhinanthus minor):

We put those [meadows] in but I was reluctant to put anymore in because I'd seen what that type of management had done you see. I knew that cutting very late let yellow rattle take hold in those two pieces...there's little else in them now. The other bits nearer home had been cut earlier on occasion and there was never as much of the stuff in them...I had watched those two bits over the years and so could see what would happen to the rest...they'd be overrun with rattle

Embedded within the farmer's oral history was a clear understanding of the management which had led to the species' increased abundance, linking causes to their subsequent effects. More pertinent to recent conservation debates, however, is the recognition of the parasitic nature of rhinanthus minor, illustrating how its presence "had reduced grass growth" - an issue which has only recently been fully recognised by ecologists and conservationists (Westbury \& Davies 2005). While recent scientific research has investigated the controlled use of Rhinanthus minor as a positive management tool, ${ }^{28}$ the 
farmer observed its spread in terms of negative management. The farmer saw the species as a "nuisance", as "stopping good grass growth", and hence "a pest to good farming". In this respect, similar understandings - that rhinanthus minor reduces soil nutrient levels - are reached independently by farmers and conservation scientists, but with very different meanings attached to them. The farmer's oral history carries the specific understanding of the impact of the species on soil fertility, but it comes within a narrative of agricultural production and the negative impacts of the species on this production. The example highlights the critical way, advocated here, that oral histories can be drawn upon. Farmers' oral histories are not simply a recital of 'true' facts in themselves, but are layered narratives which, when unlayered and contextualised, may contain understandings of direct relevance to contemporary conservation debates. 


\section{Critiquing conservation management}

We do not wish to present a simple dichotomy, which views the oral histories as being in some way 'truer' than understandings from science. Rather, we see these oral histories as allowing space to be opened up for alternative, humanised, and populated narratives of the countryside and its managements. Opening up this space allows us to question and think critically about the currently science dominated conservation agendas and policies of the countryside. For instance, a prominent theme within current conservation schemes, is the notion of 'traditional' management, with the rhetoric of 'tradition' very important in the management of agricultural land in both study areas. In the Peak District for instance, effort is channelled in relation to hay meadows to "conserve grassland by maintaining traditional grazing and hay-cutting patterns" (DEFRA 2003: 41 emphasis added), whilst in Devon, hedges are to be conserved "on a traditional hedge-laying and coppicing cycle" (DEFRA 2005: 36). 
In the Peak District, oral histories brought into focus the extent to which recourse to such 'static' and 'stable' tradition is problematic. In this case, farmers used recollections of their past practices to question the 'traditional' management as set out by current agrienvironment schemes. An area of specific focus was the recommendation that cutting should take place no earlier than $15^{\text {th }}$ July. ${ }^{29}$ Many farmers referred to the 'normal', and indeed frequent, practice of cutting earlier than this date, which, they argued, "had taken place for centuries", and which "was a very common practice, happening year after year". Farmers' oral testimonies commonly drew on biographical events and markers which reaffirmed this timing of cutting, with one respondent for example noting that "my son often had to spend his birthday on the $11^{\text {th }}$ June in the hay field", while others drew on the common phrase of "sweet June hay" to reflect on both the practice and product of this 'tradition' of earlier cutting dates. Such oral narratives illustrate the artificial nature of (re)created or 'invented' traditions (Hobsbawm 1983). In particular, they question the extent to which practices can ever be said to have conformed to a standard pattern and instead emphasise diversity and individual nuance with respect to haymaking practices. As well as leading us to ponder the type of landscape such uniform 'traditional' practices embodied within agri-environment schemes will create, these oral histories have also opened up the question of whether farmers will take up such practices that are 'alien' to those which were actually undertaken in the past (fora detailed discussion see Riley 2006).

Similar questions are raised in the Devon study where the 'traditional' management of hedgerows distilled into agri-environment schemes was seen to reveal only a partial narrative. During a discussion with a south Devon farmer for instance, the history of the hedgerows on his farmwas brought out: 
Oh yes, at the end of the [Second World] war, father had a blitz and we went round and cut them all, but a lot of the hedges were like trees, all the way around ...some of those trees had enough rings to be more than 70 years old [...] When I was a child, I can't hardly remember any hedges that were topped ...we just hadn't got the labour to do it.

This understanding disrupts the narrative of 'traditional' hedgerow management as something which declined only as a result of increased mechanisation and associated 'grubbing' of hedges (Barnes \& Williamson 2006). More broadly, it creates space for a questioning of what these 'traditions' referred to in current conservation schemes actually represent - whether they are faithful returns to an era when hedgerows were a common feature of the landscape and their management supported a diverse range of flora and fauna, or, whether the 'traditional' management advocated in these schemes is saturated with present-centred agendas and hopes for the future. We need to recognise that hedges, as with many landscape features and habitats, are not one-dimensional physical objects. The oral histories of the people who have worked and lived on this land highlight the intricate variations of past management and provide accompanying narratives that highlight their complex social history. These narratives illustrate how changing landscapes and practices are inextricably entwined with changing technological, economic and social conditions, which have fostered shifting attitudes, values and meanings that are far from spatially or temporally static. 


\section{Concluding Discussion}

This paper has considered the potential of an oral history approach to heed the recent calls within geography for a more nuanced understanding of the transformation of the agricultural landscape 'from the ground' (Morris and Evans 2004; Setten 2005). Within the paper, therefore, we have sought to explore the lived, performed and embodied understandings of landscape and landscape change, embedded within the oral histories of farmers, farm workers and farming families 'on the ground'. More specifically, the paper has sought to develop and apply a more sophisticated, and less mechanistic methodology in tapping into these oral histories. A number of methodological techniques and devices have been elucidated. For example, while previous research tended to approach the theme of interview location in relation to issues such as respondent safety and comfort, the paper has considered the issue in terms of its positive potential. It has been seen, through interviewing-in-the-field, that the landscape may act as a topographical starting point provoking memories, stories and discussions 'on the hoof', as interviews moved around the farm, as well as providing markers within respondents' narratives which could be returned to and re-approached as the discussions developed. This was seen not only in terms of stimulating memories and structuring narratives, but also through aiding the articulation of certain issues (through visual comparison and practical demonstration for example), and through affording the freedom to follow more incidental, yet no less pertinent, paths of discussion with artefacts and landscape features stimulating new trajectories for discussion. The premeditated use of artefacts - both those taken to the interview, and those brought forward by respondents - proved a useful methodological device in uncovering detailed oral histories. Such artefacts were commonly found to embody complex histories which oral histories narrated and untangled. 
More fundamentally, in uncovering these oral histories, the paper has opened up space for a contemplation of the detailed and complex understandings that reside within them. The paper has shown that oral histories can help give a fuller appreciation, not only of what changes have taken place in the landscape, but also how and why these changes took place. Such histories should not be narrated and written solely by farm owners or principal farm operators, but the myriad of individuals who have worked the landscape, both over long time periods as well as those with a more transient involvement. Incorporating the histories of such individuals not only goes some way to redressing their marginalisation from previous research on farming cultures, but also reveals their often crucial, yet largely unrecorded, role in shaping landscape change. These individual and collective oral histories have the potential to unpick and unlayer complex histories of landscape change, with events, practices and processes provided with a deeper temporal framework and more nuanced cultural context. Oral histories, therefore, embody intricate understandings of landscape and changing farm practices, which may feed directly into contemporary debates about landscape conservation and the consequences of particular management practices.

These oral histories have both theoretical and practical applications. At a practical level, we have demonstrated that when put into context, oral histories can complement scientific experiments into the impacts of particular changes in management. More broadly however, the embodied understandings and complex social histories brought forward by these oral histories, open up space for contemplation of contemporary landscape management and conservation. In light of these humanised accounts, therefore, we may start to question both 
the efficacy of particular conservation managements as well as ask the broader question of whose voice is allowed to speak for the past and future of the countryside.

\section{Acknowledgements}

The authors would like to acknowledge the AHRC (Innovation Award: R15611) and the University of Nottingham who funded the research projects from which this paper is taken. They would also like to thank conference participants at the University of Exeter and University of York where earlier drafts of this paper were presented, and to the editor and anonymous referees for their very constructive comments. 


\section{Notes}

\section{Figures}

Figure 1 - Uncovering History

Figure 2 - Cocking Hay into a Tri-pod

Figure 3-(Re)reading the changing landscape

\section{References}

Barnes, G. \& Williamson, T. (2006) Hedgerow History: Ecology, History and Landscape Character. Macclessfield: Windgather.

Barnett, C. (1998) The cultural worm turns: fashion or progress in humangeography?, Antipode 30: 379-94.

Brassley, P. (1996) Silage in Britain, 1880-1990: the delayed adoption of an innovation, Agricultural History Review 44: 63-87.

Brown, T., Hawken, S., Griffith, F., Franklin, L. \& Hawkins, C. (2004) Science, landscape archaeology and public participation: the Community Landscape Project, Devon, UK, Public Archaeology 3: 217-226.

Burgess, J., Clark, J. \& Harrison, C. (2000) Knowledges in action: an actor network analysis of a wetland agri-environment scheme, Ecological Economics 35: 119132.

Burgess, R. G. (1984) In the Field: an Introduction to Field Research. London: Routeledge.

Confino, A. (1997) Collective memory and cultural history: problems and methods, American Historical Review 102: 1386-1403.

Connerton, P. (1989) How Societies Remember. Cambridge: Cambridge University Press.

Cook, I. \& Crang, M. (1995) Doing Ethnographies. Norwich: CATMOG.

Cook, I., Crouch, D., Naylor, S. \& Ryan, J. (2000) Cultural Turns/Geographical Turns: Perspectives on Cultural Geography. Harlow: Prentice Hall.

Cosgrove, D. (1984) Prospect, perspective and the evolution of the landscape idea, Transactions of the Institute of British Geographers 10: 45-62.

Cosgrove, D. E. \& Daniels, S. (eds), (1988) The Iconography of Landscape: Essays on the Symbolic Representation, Design and Use of Past Environments. Cambridge: Cambridge University Press.

Cresswell, T. (2002) Landscape and the obliteration of practice, in Anderson, K., Domosh, M., Pile, S. and Thrift, N. (eds) Handbook of Cultural Geography. London: Sage, pp. 269-81.

DEFRA. (2002) The Countryside Stewardship Scheme: Information and How to Apply. London: HMSO.

DEFRA. (2003) The Countryside Stewardship Scheme: Information and How to Apply. London: HMSO. 
DEFRA. (2005) Environmental Stewardship: Entry Level Stewardship Handbook - Terms and Conditions and How to Apply. London: HMSO.

Denzin, N. (1989) Interpretive Biography. London: Sage.

Denzin, N. K. \& Lincoln, Y. S. (2003) Strategies of Qualitative Inquiry. London: Sage.

DETR/MAFF. (2000) Rural White Paper - Our Countryside: the Future - A Fair Deal for Rural England. London: HMSO.

Duncan, J. (1995) Landscape geography, 1993-94, Progress in Human Geography 19: 414422.

Edwards, K. C. (1973) The Peak District. London: Collins.

Evans, G. E. (1965) Ask the Fellows who Cut the Hay. London: Faber and Faber.

Evans, G. E. (1970) Where Beards Wag All. London: Faber and Faber.

Evans, G. E. (1975) The Days we have Seen. London: Faber and Faber.

Evans, G. E. \& Gentleman, D. (1993) The Crooked Scythe: an Anthology of Oral History. London: Faber and Faber.

Gluck, S. B. \& Patai, D. (1991) Women's Words: the Feminist Practice of Oral History. New York ; London: Routledge.

Gray, J. (1996) Cultivating farm life on the borders: Scottish hill sheep farms and the European Community, Sociologia Ruralis 36: 27-\&.

Green, A. (2000) Coffee and bun, Sergeant Bonnington and the tornado: myth and place in Frankton Junction, Oral History 28: 26-34.

Grele, R. J. (1979) Listen to their voices: two case studies in the interpretation of oral history interviews, Oral History 7: 33-42.

Grele, R. J. (1998) Movement without aim: methodological and theoretical problems in oral history, in Perks, R. and Thomson, A. (eds) The Oral History Reader. London: Routledge, pp. 38-52.

Heckathorn, D. D. (2002) Respondent-driven sampling II: deriving valid population estimates from chain-referral samples of hidden populations, Social problems 49: 11-34.

Hobsbawm, E. (1983) Introduction: inventing traditions, in Hobsbawm, E. and Ranger, T. (eds) The Invention of Tradition. Cambridge: Cambridge University Press, pp. 1-14.

Hobsbawm, E. (1997) On History. London: Weidenfeld and Nicolson.

Hoelscher, S. \& Alderman, D. H. (2004) Memory and place: geographies of a critical relationship, Social \& Cultural Geography 5: 347-355.

Holloway, L. (1999) Understanding climate change and farming: scientific and farmers' constructions of 'global warming' in relation to agriculture, Environment and Planning A 31: 2017-2032.

Holloway, L. (2000) 'Hell on earth and paradise all at the same time': the production of smallholding space in the British countryside, Area 32: 307-315.

Hoskins, W. G. (1954) Devon. London: Collins.

Howkins, A. (1994) Inventing everyman: George Ewart Evans, oral history and national identity, Oral History 22.

Howkins, A. (1998) A country at war: Mass-Observation and rural England, Rural History 9: 75-97.

Hughes, J. \& Huntley, B. (1988) Upland hay meadows in Britain - their vegetation, management and future, in Birks, H. H., Birks, H. J., Kaland, P. E. and Moe, D. (eds) The Cultural Landscape: Past, Present and Future. Cambridge: Cambridge University Press, pp. 91-110. 
Jones, A. (2001) We plough the fields, but what do we scatter? A look at the science and practice of grassland restoration, British Wildlife April: 229-235.

Kindon, S. (2003) Participatory video in geographic research: a feminist practice of looking?, Area 35: 142-153.

Knape, J. (1955) Tripod hay in the north, Agriculture LXII: 6-8.

Lorimer, H. (2003) Telling small stories: spaces of knowledge and the practice of geography, Transactions of the Institute of British Geographers 28: 197-217.

MAFF. (1997) Environmental Monitoring Report for the South West Peak ESA 1993-1996. London: HMSO.

Marcombe, D. (1995) Sounding Boards: Oral Testimony and the Local Historian. University of Nottingham: Department of Adult Education.

Martin, J. (2000) The Development of Modern Agriculture: British Farming since 1931. London: Macmillan Press.

Mason, J. (1996) Qualitative Researching. London: Sage.

Matless, D. (1998) Landscape and Englishness. London: Reaktion.

McEachern, C. (1992) Farmers and conservation - conflict and accommodation in farming politics, Journal of Rural Studies 8: 159-171.

McHenry, H. (1997) Wild flowers in the wrong field areweeds! Examining farmers' constructions of conservation, Environment and Planning A 30: 1039-1053.

Mitchell, D. (2003) Dead labor and the political economy of landscape - California living, California dying, in Anderson, K., Domosh, M., Pile, S. and Thrift, N. (eds) Handbook of Cultural Geography. London: Sage, pp. 233-248.

Morris, C. (2006) Negotiating the boundary between state-led and famer approaches to knowing nature: an analysis of UK agri-environment schemes, Geoforum 37: 113127.

Morris, C. \& Evans, N. (2004) Agricultural turns, geographical turns: retrospect and prospect, Journal of Rural Studies 20: 95-111.

Morris, C. \& Evans, N. J. (1999) Research on the geography of agricultural change: redundant or revitalized, Area 31: 349-358.

NCC (Nature Conservancy Council).(1984) Nature Conservation in Great Britain. Shrewsbury: Nature Conservancy Council.

Nevins, A. (1996) Oral history: how and why it was born, in Dunaway, D. and Baum, W. (eds) Oral History: an Interdisciplinary Anthology. London: Alta Mira, pp. 7-30.

Ohrn, B. K. (1975) The photoflow of family life, Folklore Forum 13: 27-36.

PDNPA (Peak District National Park Authority). (2000) Biodiversity Action Plan: Peak District National Park. Bakewell: Peak District National Park Authority.

Philo, C. (1992) Neglected rural geographies: a review, Journal of Rural Studies 8: 193 207.

Philo, C. (1998) Reading Drumlin: academic geography and a student geographical magazine, Progress in Human Geography 22: 344-367.

Portelli, A. (1981) The peculiarities of oral history, History Workshop 12: 96-107.

Powell, B. \& Westacott, N. (1997) The Women's Land Army. Stroud: Sutton.

Raedeke, A. H., Green, J. J., Hodge, S. S. \& Valdivia, C. (2003) Farmers, the practice of farming and the future of agroforestry: an application of Bourdieu's concepts of field and habitus, Rural Sociology 68: 64-86.

Riley, M. (2003) Changing Farm Practices and Nature Conservation: Hay and Silage Production in the Peak District Since 1940. Nottingham: Unpublished PhD thesis University of Nottingham. 
Riley, M. (2005) Silent meadows: the uncertain decline and conservation of hay meadows in the British landscape, Landscape Research 30: 437-458.

Riley, M. (2006) Reconsidering conceptualizations of farmer conservation behaviour: the case of conserving hay meadows, Journal of Rural Studies 22: 337-353.

Riley, M. \& Harvey, D. (2005) Landscape archæology, heritage and the community in Devon: an oral history approach, International Journal of Heritage Studies 11: 269288.

Riley, M. (in press) Experts in their fields: farmer-expert knowledges and environmentally friendly farming practices Environment and Planning $A$

Ross, E. \& Wilentz, S. (1981) Britain - the History Workshop Movement, Radical History Review: 179-181.

Rothbaum, H. P. (1963) Spontaneous combustion of hay, Journal of Applied Chemistry 13: 291-302.

Seale, C. \& Kelly, M. (1998) Coding and analysing data, in Seale, C. (ed.) Researching Society and Culture. London: Sage, pp. 146-163.

Setten, G. (2004) The habitus, the rule and the moral landscape, Cultural Geographies 11: 389-415.

Setten, G. (2005) Farming the heritage: on the production and construction of a personal and practised landscape heritage, International Journal of Heritage Studies 11: 6779.

Short, B. \& Watkins, C. (1994) The National Farm Survey of England and Wales, Area 23: 288-293.

Short, B., Watkins, C., Foot, W. \& Kinsman, P. (2000) The National Farm Survey 19411943: State Surveillance and the Countryside in England and Wales in the Second World War. Oxford: Cab International.

Slim, H. \& Thompson, P. (1998) Ways of listening, in Perks, R. and Thompson, A. (eds) The Oral History Reader. London: Routeledge, pp. 114-125.

Smith, R. S., Buckingham, H., Bullard, M. J., Sheil, R. S. \& Younger, A. (1996) The conservation management of mesotrophic (meadow) grassland in northern England. Effects of grazing, hay cut date and fertilizer on the vegetation of a traditionally managed sward, Grass and Forage Science 51: 278-291.

Smith, R. S. \& Jones, L. (1991) The phenology of mesotrophic meadowland in the Pennine Dales, Northern England: historic hay cutting dates, vegetation variation and plant species phenology, Journal of Applied Ecology 28: 42-49.

Smith, R. S., Shiel, R. S., Millward, D., Corkhill, P. \& Sanderson, R. A. (2002) Soil seed banks and the effects of meadow management on vegetation change in a 10-year meadow field trial, Journal of Applied Ecology 39: 279-293.

Thompson, P. (1981) Life histories and the analysis of social change, in Bertaux, D. (ed.) Biography and Society: the LifeHistory Approach in the Social. London: Sage, pp. 289-306.

Thompson, P. (1988) The Voice of the Past: Oral History. Oxford: Oxford University Press. Thomson, A. (1999) Making the most of memories: the empirical and subjective value of oral history, Transactions of the Royal Historical Society 9: 291-301.

Titon, J. T. (1980) The life story, Journal of American Folklore 93: 276-292.

Tryer, N. (1996) They Fought in the Fields - the Women's Land Army: The Story of a Forgotten Victory. London: Sinclair-Stevenson. 
Tsouvalis, J., Seymour, S. \& Watkins, C. (2000) Exploring knowledge-cultures: precision farming, yield mapping, and the expert-farmer interface, Environment and Planning A 32: 909-924.

Valentine, G. (1997) Tell me about..... Using interviews as a research methodology, in Flowerdew, R. and Martin, D. (eds) Methods in Human Geography. Harlow: Longman, pp. 109-126.

Walker, A. L. \& Moulton, R. K. (1989) Photo albums: images of time and reflections of self, Qualitative Sociology 12: 155-182.

Westbury, D. B. \& Davies, A. (2005) Yellow rattle - its natural history and use in grassland diversification, British Wildlife December: 93-98. 
${ }^{1}$ See for example Cosgrove (1984), Cosgrove and Daniels (1988), Duncan (1995), Matless (1998).

${ }^{2}$ Although, as our later examples will illustrate, these oral traditions become inextricably linked with, and drawn upon in, the life histories of respondents.

${ }^{3}$ Burgess (1984: 126) has termed this 'topical autobiography'.

${ }^{4}$ Moving towards a fuller understanding of these relationships, a number of studies have employed in-depth qualitative methodologies (e.g. Burgess et al. 2000; McHenry 1997), with some particularly insightful ethnographic studies (Gray 1996; McEachern 1992). A wide range of different issues have been considered, including that of precision farming (Tsouvalis et al. 2000) and global warming (Holloway 1999).

${ }^{5}$ Since the publication of Howkins' paper there have been a few more studies which have begun to reconsider the history of rural areas in the Second World War period - see for example Martin (2000).

${ }^{6}$ Interesting inferences to these issues can, however, be found in the more numerous studies considering the role of the Women's Land Army (see for example Powell \& Westacott 1997; Tryer 1996).

${ }^{7}$ In addition to their conservation within the UK's main agri-environment programmes, smaller projects have been initiated to investigate the feasibility of re-instituting hay meadows through seed reintroduction (Jones 2001).

${ }^{8}$ These were based on land classification mapping (see MAFF 1997) with 6 parishes considered in the Peak District and 5 broader areas focussed on in the Devon Study (see Riley 2003; Riley \& Harvey 2005 for a fuller discussion of these practical issues).

${ }^{9}$ The interviews were recorded using a minidisc recorder, transcribed verbatim, and coded manually (after Seale \& Kelly 1998).

${ }^{10}$ Some scholars (see for example Gluck \& Patai 1991; Kindon 2003) have considered the use of video recording of interviews, which would have obvious applications to an approach similar to this in recording non-verbal elements. ${ }^{11}$ War Agricultural Executive Committees who were responsible for the WW2 'Plough-up' campaign (see Short et al., 2000)

${ }^{12}$ This can be compared to other interviews where markers in the narrative could not be so easily reached by the interviewer from which to re-approach particular themes and issues: "You mentioned earlier, before we started to talk about the rationing, you mentioned a machinery pool, in the war, that had been close to here......".

${ }^{13}$ The National Farm survey contains returns for individual farms and is accompanied by maps showing the holding boundaries of these farms - see Short et al (2000) for a full discussion.

${ }^{14}$ Issues commonly questioned by farmers relating to the survey were inaccuracies in the mapping of farm boundaries and land ownership (see Harvey \& Riley, 2005: 23-24).

${ }^{15}$ An interesting discussion of the pattern of mowing with tractors and the safety of birds which mirrors the issue raised by this farmer is presented by Andrews and Rebane (1994).

${ }^{16}$ Interestingly, it is these travelling gangs that are at the centre of George Ewart Evans's (1965) oral history study $A s k$ the Fellows Who Cut the Hay.

${ }^{17}$ Either when respondents were already outside when revisited and the discussion flowed on from there, or when inthe-field interviews were prearranged at the previous meeting.

${ }^{18}$ All names of respondents have been changed.

${ }^{19}$ This was seen in particular in the Peak District study where silage production has only become more widespread since the 1960s and which was referred to as "a practice of the younger generations" and comments such as "hay was the only method in my day and that's why I prefer it"

${ }^{20}$ This was a community based archaeological programme based at the University of Exeter and funded by the Heritage Lottery Fund (see Brown et al. 2004).

${ }^{21}$ There are interesting narrative issues here relating to the language of 'improving' and 'controlling' the land, in which farmers who have worked under the postwar productivist ethos, view nature as something to be controlled or 'mastered' (for interesting discussions of these issues see Burgess et al., 2000; McHenry, 1997).

${ }^{22}$ Within the figure 2, the farmer can be seen demonstrating how the 'cut' edge of the bale was turned outwards to deflect water, in a fashion that was similar (he argued) "to how the thatch is cut to turn water from the roof of a thatched cottage".

${ }^{23}$ Referring to the spontaneous combustion of hay (see Rothbaum 1963)

${ }^{24}$ In the case of Figure 3 the former meadow is now indistinguishable from grazed pastureland.

${ }^{25}$ A number of commentators have referred to the heavily 'scientised' nature of these schemes which have been largely devised and formulated by scientific experts - see Morris (2004) for a useful discussion.

${ }^{26}$ Phenology is the study of flowering, breeding and migration, particularly in relation to climatic conditions.

${ }^{27}$ The Countryside Stewardship Scheme (CSS) is a national scheme in the UK, administered by the Department for Environment Food and Rural Affairs. It offers payments to farmers and land managers to enhance and conserve landscapes, their wildlife, heritage and history. The national, but broadly analogous, Environmental Stewardship Scheme superseded CSS in 2005.

${ }^{28}$ Davies et al (1997) argue that the controlled use of Rhinanthus minor can reduce soil nutrient levels and allow the continuation of less vigorous species and hence increase biodiversity.

${ }^{29}$ The rationale for this practice is to 'ensure that ground nesting birds have successfully completed their breeding season and that grasses and herbs are allowed adequate time to set seed' (DEFRA 2002: 15). 